\title{
Amantadine and phenytoin: patent protected cases of drug repositioning
}

\begin{abstract}
Repositioning of old drugs in new indications is a hot topic. However, there are some hurdles to take, and one is related to financial attractiveness. We will discuss two examples to solve this problem based on patents: phenytoin cream for neuropathic pain and amantadine extended release for dyskinesia and other neurological disorders, and discuss amantadine, its history of repositioning and its patents in more detail. Both molecules are respectable old compounds, phenytoin was synthesized more than a century ago, and amantadine in the 50s of last century.

Amantadine was first recognized as an antiviral compound in the 60s of last century, and was approved by the FDA for flu prophylaxes in 1966. Parkinson was its first repositioning indication, triggered by a case study in 1968. Subsequently a great variety of indications were explored, from fatigue in multiple sclerosis, enuresis nocturna, ADHD, up to pathological gambling and recovery after head injury. Amantadine is currently developed as an extended release formulation for levodopa-induced dyskinesia in Parkinson's disease (preapproval phase). It is protected by a patent from 2009, claiming a special formulation and time of intake.
\end{abstract}

While its antiviral mechanism of action has been clarified, the mechanisms of action in other indications are still quite enigmatic. At the end of last century, it was stipulated that amantadine and comparable drugs with unexplained mechanisms may deserve additional studies to enfold its full therapeutic potential. Based on an analysis of the clinical perspectives for amantadine at that time it was felt necessary to developing an infrastructure for funding research on new purposes for older drugs after they lose patent protection. Nearly 2 decades later such recommendation still remains valid.

Keywords: Drug" Repositioning" Repurposing" Parkinson, flu= Dyskinesia= ADS-5102- Patent

Submitted: 28 March 2017; Accepted: 14 April 2017; Published online: 01 May 2017

\section{Introduction}

It is clear that the costs for drug development are increasing due to more and more hurdles to take for the pharmaceutical companies. This leads to high prices of drugs, to be paid by our society. Repositioning of old drugs in new indications is recognized increasingly as a way to provide patients in our society with cheaper therapies [1]. In PubMed, since 2014, more than 200 publications are indexed based on the keywords drug repositioning each year,
Jan M. Keppel Hesselink* Professor of Molecular Pharmacology, University of Witten/Herdecke, Germany *Author for correspondence: jan@neuropathie.nu 


\section{Results by year}

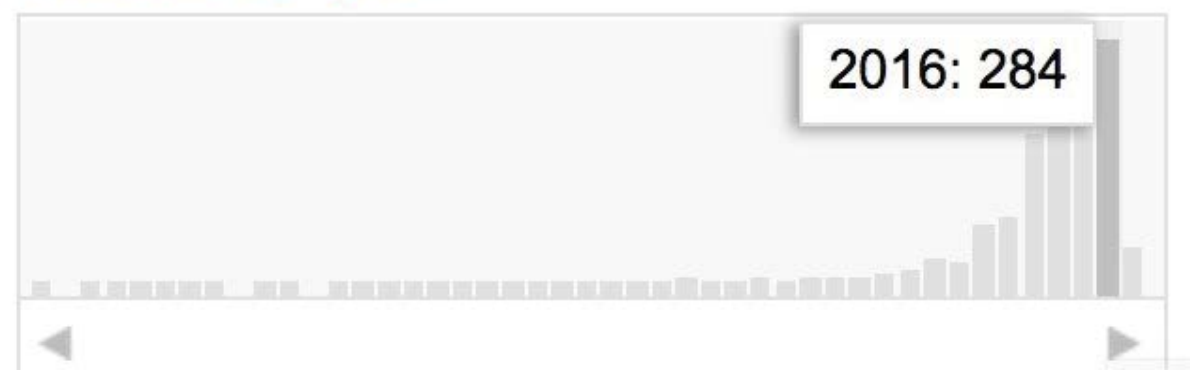

Figure 1. publications indexed in PubMed based on the keywords 'drug repositioning': a clear increase in publications each year since 2008 .

amantadine extended release and phenytoin topical cream.

\section{Amantadine: repositioned as an extended release formulation}

L-adamantanamine (amantadine) is a symmetrical C-10 primary amine with a remarkable cyclic structure (Figure 2), known since the 60s of last century as an antiviral compound, is well absorbed after oral administration and is excreted for more than $90 \%$ in unmetabolized form in the urine $[5,6]$.

The compound and its derivatives were patented in 1961, and introduced under the brand name Symmetrel, by du Pont de Nemours \& Co., Inc [7]. The FDA approval for flu prophylaxis dates from 1966. A new formulation of the drug is currently under development as ADS- 5102 by Adamas Pharmaceuticals, and might soon become the first FDA-approved drug for the treatment of levodopa-induced dyskinesia in patients with Parkinson's disease [8]. In April 2015, the FDA granted orphan drug status to ADS-5102 for this indication.

The compound has a long history of repositioning, perhaps related to the fact that its mechanisms of action are still debated and might still hold some surprises. Already early in its history, its mechanisms of action were unclear [9]. This remained the case.

Amantadine was initially introduced as an antiflu compound, and some of its more recent putative indications are aggression and severe autism in children, delayed ejaculation and walking impairment in multiple sclerosis [10-15]. For the last indication, a special extended release formulation has been tested. Other new formulations of this old drug are underway [16].

Its first main repositioning from an anti-flu compound to an anti-Parkinson drug was initiated by a case observation in 1968 of a 58 -year-old woman with

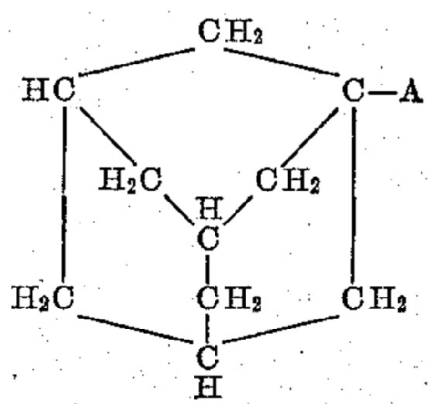

Figure 2. Structure of amantadine and its derivatives from the Du Pont patent in 1961.

moderately severe Parkinson's disease. This patient told the treating neurologist that while talking amantadine hydrochloride $100 \mathrm{mg}$ tablets to prevent the flu, she experienced a remarkable remission in her symptoms of rigidity, tremor, and akinesia [17]. Although the compound is hydrophilic it easily penetrates the bloodbrain barrier, due to active transport probably via a proton-coupled organic cation antiporter [18].

\section{Search for amantadine's mechanisms of action}

Clearly, the mechanism of action of amantadine related to the various indications listed in (Table 1) will be quite different, depending on the indication. While the molecular target is clear for its antiviral mechanism of action, it remains quite clouded for the other indications. Based on in vitro experiments the first hypothesis supporting the anti-viral activity of the drug was thought to be a result of the inhibition of the virus by the drug to penetrate into the host cells [35]. Subsequently its anti-viral effect was hypothized to be related to viral uncoating and inhibition of its replication and more recently amantadine was identified as an influenza A M2 proton channel Inhibitor, a clear molecular target [36,37].

In 1970 Grelak et al. suggested amantadine may release dopamine and catecholamines from neurons, 


\begin{tabular}{|ll|}
\hline Table 1: Potential repositioning & indications for amantadine \\
\hline Indication & Landmark paper \\
\hline Flu prophylaxis & Herman 1960 \\
\hline Parkinson & Schwab 1969 \\
\hline Huntington & Scotti 1971 [19] \\
\hline Catalepsy & Zetler, Simon 1970 [20,21] \\
\hline Enuresis & Ambrosini 1984 [22] \\
\hline Fatigue & Marray 1985 [23] \\
\hline Cocaine withdrawal & Tennant 1987 [24] \\
\hline Aggression-agitation & Chandler 1988 [25]; King 2001 \\
\hline Traumatic brain injury & [26] \\
\hline ADHD & Gualtieri 1989 [27] \\
\hline Frontal lobe syndrome & Masters 1997 [28] \\
\hline $\begin{array}{l}\text { Dopa induced dyskinesia in } \\
\text { Parkinson }\end{array}$ & Kraus 1997 [29] \\
\hline Cancer Pain & Rajput 1997 [30] \\
\hline Dementia in Parkinson & Pud 1998 [31] \\
\hline Pathological gambling & Inzelberg 2006 [32] \\
\hline
\end{tabular}

based on a number of experiments in dogs [38]. The same hypothesis was supported based on experiments in mice, and the authors suggested that the effects of amantadine in Parkinsonism were triggered by an amphetamine-like mechanism, the release of neuronal catecholamine's [39].

In the early 90s new data linked its mechanism of action to the antagonism of the drug of NMDA receptors [40,41]. However, in 1998 Goetz defined its antiparkinsonian mechanism of action to be (still) obscure. He stressed the antidyskinetic activity of the drug, in the absence of any exacerbation of Parkinsonism, and suggested that this implied that its mechanism of action was neither dopaminergic nor cholinergic, supporting a focus on the NMDA system. Interestingly, amantadine remained the only glutamate receptor antagonists clinically used to treat Parkinson, and compounds such as memantine and remacemide failed to reduce dyskinesias, suggestive for a hitherto hidden mechanism of action in this field [42]. It seems possible to defend the hypothesis that compounds with an unknown mechanism of action might have high changes as drugs for repositioning.

\section{Early repositioning lessons}

Goetz in 1998 completed his mechanistic analysis by a number of observations related to the repositioning's potential of amantadine. He pointed out that amantadine as an old drug providing new lessons to the patient, the practicing neurologist, and the research scientist. Secondly amantadine is a compound that was at that time already approved by the FDA, is inexpensive and devoid of troublesome side effects. He completed his analysis with a clear recommendation related to our topic of repositioning:

"It would be wise to reflect on numerous other agents with unexplained mechanisms that may deserve additionalstudy. Unfortunately, there is rarely support from pharmaceutical companies for investigators interested in working with old drugs, and economic priority for new compounds places such research at a competitive disadvantage. Developing an infrastructure for funding research on older chemicals after they lose patent protection but remain clinically useful is essential for continued research on available drugs. This infrastructure is also necessary to pursue further analysis of their mechanisms of action in the context of advances in molecular and submolecular neurologic function."

\section{Current repositioning in dyskinesia and walking impairment in MS}

ADS-5102 is currently Adamas' end of phase III owned product candidate and is defined by the company as an extended-release version of amantadine, intended for once daily administration at bedtime. This specific formulation is said by the company to be designed to improve upon the pharmacokinetic (PK) profile of immediate-release amantadine, in order to reach enhanced efficacy with a safe tolerability profile. In pharmacokinetic studies conducted by the company, ADS-5102 was said to induce high plasma levels of amantadine in the early morning that are sustained throughout the afternoon and lower levels in the evening [43]. The company positions this amantadine formulation as 'chronosynchronous amantadine therapy'. They submitted a New Drug Application (NDA) for this indication to the U.S. Food and Drug Administration in October 2016. Currently the company also explores ADS5102 for repositioning as a treatment of walking impairment in multiple sclerosis (MS) patients and considers developing it for other indications in Parkinson's disease, post stroke walking impairment, and side effects induced by anti-psychotic drugs, such as tardive dyskinesia, akathesia and weight gain [44].

\section{Financial compensation of repositioning efforts via patents}

Finding financial compensation for repositioning of an old drug in a new indication is recognized as a major hurdle to take for developers. One solution not discussed often is via patents.

Adamas Pharmaceuticals, Inc. filed a patent in December 2009 on the methods of nighttime administration of amantadine to reduce sleep disturbances in patient undergoing treatment with amantadine, as well as compositions of extended release amantadine that are suitable for nighttime 
administration [45]. Clearly a novel combination of the compound amantadine, a new formulation (extended release) and time of intake (before nighttime). The clinical problem solved by the patent was that amantadine therapy administered to a patient shortly before they wish to sleep (e.g., at bedtime) may cause insomnia and sleep disturbance, and the inventors identified a need for a new amantadine therapy which can be taken by the patient before they go to sleep, leading to a suitable plasma concentration of amantadine when they wake up, e.g. in the morning. Basically, the invention solved the clinical problem of side-effects of the immediate release formulation in use. A second aspect of the patent was related to methods of treating other indications, such as brain injury, brain trauma, dementia, Alzheimer's disease, stroke, Huntington's disease, ALS, Multiple Sclerosis, neurodegenerative diseases, dementias, cerebrovascular conditions, movement disorders, cranial nerve disorders and neuropsychiatric disorders. The same extended release formulation could be taken in these indications less than about three hours before bedtime. Adamas thus created a patent based on a new formulation, linked to off-label indications.

\section{Phenytoin cream formulation repositioning strat- egy}

Our interest in repositioning originated around 2010 when looking for solutions to treat neuropathic pain [46]. In our institute for neuropathic pain we have developed topical creams since that period, containing analgesics and co-analgesics such as ketamine for the treatment of a variety of neuropathic pain syndromes, such as pain in diabetic neuropathy, chemotherapy induced neuropathy, chronic idiopathic axonal neuropathy, CRPS and small fibre neuropathy [47]. We discovered that certain topical formulations support the analgesic efficacy of said analgesics, and unraveled its mechanism of action [48]. Since 2016 we also found that the old anti-epileptic compound phenytoin has a good analgesic effect in patients, among which patients suffering from small fibre neuropathy $[49,50]$.

Phenytoin is already known in the clinic since 80 years! (Figure 3) [51]. we also found that phenytoin can augment the analgesic effects of other (co-)analgesics [52]. This was an augmentation of efficacy, time to onset of efficacy and duration. Drug combination

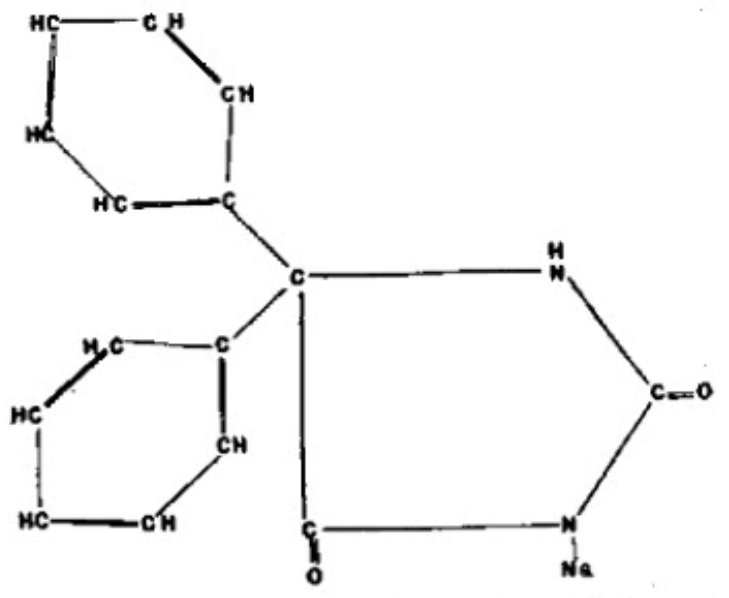

Figure 3. chemical structure of phenytoin, as first published by the inventors and neurologists Merrit and Putnam 80 years ago.

therapy is also currently a hot topic within the field of repositioning [53]. Thus, we concluded that the clinical problem of insufficient therapeutic effects of current analgesics in neuropathic pain in a cohort of patients can be solved by applying topically analgesics in selected formulation, together with phenytoin, and by phenytoin itself. Two patents protect this invention: topical phenytoin for use in the treatment of peripheral neuropathic pain' and 'topical pharmaceutical composition containing phenytoin and a (co-)analgesic for the treatment of chronic pain'.

\section{Conclusion}

Repositioning of old drugs in off-label indications is a hot topic, increasingly recognized as valuable for our patients and society. One key problem is to create a clear financial incentive for developing old drugs in new formulations. We presented two examples of patent strategies for the repositioning of old drugs in new formulations: amantadine as an extended release in a variety of neurological indications and phenytoin as a topical cream with and without co-analgesics in neuropathic pain.

\section{Conflict of Interest}

The author is one of the patent holders of two patents related to topical phenytoin formulations: topical phenytoin for use in the treatment of peripheral neuropathic pain' and 'topical pharmaceutical composition containing phenytoin and a (co-)analgesic for the treatment of chronic pain'. 


\section{References}

1. Langedijk J, Mantel-Teeuwisse AK, Slijkerman DS, Schutjens $\mathrm{MH}$. Drug repositioning and repurposing: terminology and definitions in literature. Drug Discov Today, 20(8): 1027-1034 (2005).

2. Tan Z, Chaudhai R, Zhang S. Polypharmacology in Drug Development: A Minireview of Current Technologies. ChemMedChem, 11(12): 1211-1218 (2016).

3. Klug DM, Gelb MH, Pollastri MP. Repurposing strategies for tropical disease drug discovery. Bioorg Med Chem Lett, 26(11): 2569-2576 (2016).

4. Roundtable on Translating Genomic-Based Research for Health; Board on Health Sciences Policy; Institute of Medicine. Washington (DC): National Academies Press (US); 2014 Aug 8.

5. Herrman, E. C., et al. Antiviral activity of L-adamantanamine (amantadine). Proc Soc Exp Biol Med, 103: 625 (1960).

6. Aoki FY, Sitar DS. Clinical pharmacokinetics of amantadine hydrochloride. Clin Pharmacokinet, 14: 35-51 (1988).

7. Du Pont Patent. Pharmaceutical compositions and methods utilizing 1-aminoadamantane and its derivatives US 3310469 A. Priority date August 28, 1961.

8. Adamas Presents Additional Open-Label, Long-Term Safety and Efficacy Data on ADS-5102 at the First Pan American Parkinson's Disease and Movement Disorders Congress.

9. Goedemans WT. Adamantanamine, multiple mode of action?. Zentralblatt fur Bakteriologie, Parasitenkunde, Infektionskrankheiten und Hygiene, 214(2): 289-291 (1970).

10. Hay AJ. The action of amantadines against influenza $A$ viruses. Semin Virol, 3: 21-30 (1992).

11. McGrane IR, Loveland JG, Zaluski HJ. Adjunctive Amantadine Treatment for Aggressive Behavior in Children: A Series of Eight Cases. J Child Adolesc Psychopharmacol, 26(10): 935-938 (2016).

12. Ellul P, Rotgé JY, Choucha W. Resistant Catatonia in a HighFunctioning Autism Spectrum Disorder Patient Successfully Treated with Amantadine. J Child Adolesc Psychopharmacol, 25(9): 726 (2015).

13. Mohammadi MR, Yadegari N, Hassanzadeh E, Farokhnia M, Yekehtaz H, Mirshafiee O, Akhondzadeh S. Double-blind, placebo-controlled trial of risperidone plus amantadine in children with autism: a 10-week randomized study. Clin Neuropharmacol, 36(6): 179-184 (2013).

14. Abdel-Hamid IA, Elsaied MA, Mostafa T. The drug treatment of delayed ejaculation. Transl Androl Urol, 5(4): 576-591 (2016).

15. Adamas Pharmaceuticals, Inc. Press release. Adamas to Present New ADS-5102 Data from Phase 2 Trial in Walking Impairment Associated with Multiple Sclerosis at ACTRIMS Forum 2017.

16. Lungare S, Bowen J, Badhan R. Development and Evaluation of a Novel Intranasal Spray for the Delivery of Amantadine. $J$ Pharm Sci, 105(3): 1209-1220 (2016).

17. Schwab RS, England AC, Poskanzer DC, Young RR. Amantadine in the treatment of Parkinson's disease. JAMA, 208(7): 1168-1170 (1969).

18. Suzuki T, Aoyama T, Suzuki N, Kobayashi M, Fukami T, Matsumoto Y, Tomono K. Involvement of a proton-coupled organic cation antiporter in the blood-brain barrier transport of amantadine. Biopharm Drug Dispos, 37(6): 323-335 (2016).

19. Scotti G, Spinnler H. Amantadine and Huntington's chorea. $N$
Engl J Med, 285(23): 1325-1326 (1971).

20. Zetler G. Anticataleptic actions of amantadine hydrochloride. Naunyn Schmiedebergs Arch Pharmakol, 266(3): 276-278 (1970).

21. Simon P, Malatray J, Boissier JR. Antagonism by amantadine of prochlorpemazine-induced catalepsy. J Pharm Pharmacol, 22(7): 546-547 (1970).

22. Ambrosini PJ, Fried J. Preliminary report: amantadine hydrochloride in childhood enuresis. J Clin Psychopharmacol, 4(4): 223-225 (1984).

23. Murray TJ. Amantadine therapy for fatigue in multiple sclerosis. Can J Neurol Sci, 12(3): 251-254 (1985).

24. Tennant FS Jr, Sagherian AA. Double-blind comparison of amantadine and bromocriptine for ambulatory withdrawal from cocaine dependence. Arch Intern Med, 147(1): 109-112 (1987).

25. Chandler MC, Barnhill JL, Gualtieri CT. Amantadine for the agitated head-injury patient. Brain Inj, 2(4): 309-311 (1988).

26. King BH, Wright DM, Snape M, Dourish CT. Case series: amantadine open-label treatment of impulsive and aggressive behavior in hospitalized children with developmental disabilities. J Am Acad Child Adolesc Psychiatry, 40(6): 654-657 (2001).

27. Gualtieri T, Chandler M, Coons TB, Brown LT. Amantadine: a new clinical profile for traumatic brain injury. Clin Neuropharmacol, 12(4): 258-270 (1989).

28. Masters KJ. Alternative medications for ADHD. J Am Acad Child Adolesc Psychiatry, 36(3): 301-302 (1997).

29. Kraus MF, Maki PM. Effect of amantadine hydrochloride on symptoms of frontal lobe dysfunction in brain injury: case studies and review. J Neuropsychiatry Clin Neurosci, 9(2): 222230 (1997).

30. Rajput AH, Uitti RJ, Lang AE, Kumar R, Galvez-Jimenez $\mathrm{N}$. Amantadine ameliorates levodopa induced dyskinesia. Neurology, 48: 328 (1997).

31. Pud D, Eisenberg E, Spitzer A, Adler R, Friedn G, Yarnitsky $D$. The NMDA receptor antagonist amantadine reduces surgical neuropathic pain in cancer patients: a double blind, randomized, placebo controlled trial. Pain, 75(2-3): 349-354 (1998).

32. Inzelberg R, Bonuccelli U, Schechtman E, et al. Association between amantadine and the onset of dementia in parkinson's disease. Mov. Disord, 21: 1375-1379 (2006).

33. Thomas A, Bonanni L, Gambi F, Di Iorio A, Onofrj M. Pathological gambling in Parkinson disease is reduced by amantadine. Ann Neurol, 68: 400-404 (2010).

34. Stanford University. Amantadine Brand Name: Symmetrel, Symadine.

35. Hoffmann CE, Neumayer EM, Haff RF, Goldsby RA. Mode of action of the antiviral activity of amantadine in tissue culture. Journal of bacteriology, 90(3): 623-628 (1965).

36. Hay AJ. The action of amantadines against influenza A viruses. Semin Virol, 3: 21-30 (1992).

37. Llabrés S, Juárez-Jiménez J, Masetti M, et al. Mechanism of the Pseudoirreversible Binding of Amantadine to the M2 Proton Channel. J Am Chem Soc, 138(47): 15345-15358 (2016).

38. Grelak RP, Clark R, Stump JM, Vernier VG. Amantadinedopamine interaction: possible mode of action in Parkinsonism. Science, 169(3941): 203-204 (1970).

39. Strömberg U, Svensson TH, Waldeck B. On the mode of action of amantadine. J Pharma Pharmacol 22(12): 959-962 (1970). 
40. Stoof JC, Booij J, Drukalrch B. Amantadine as N-methyl-Daspartic acid receptor antagonist. Clin Neurol Neurosurg, 94: 4-6 (1992).

41. Kornhuber J, Weller M, Schoppmeyer K, Riederer P. Amantadine and memantine are NMDA receptor antagonists with neuroprotec- tive properties. J Neural Transm, 43: 91-104 (1994).

42. Merello M, Nouzeilles MI, Cammarota A, Leiguarda R. Effect of memantine (NMDA antagonist) on Parkinson's disease: a double-blind crossover randomized study. Clin Neuropharmacol, 22: 273-276 (1999).

43. Adamas Pharmaceuticals, Inc. Press release, Dec. 23, 2015. Adamas Announces Positive Top-Line Phase 3 Results of ADS5102 for the Treatment of Levodopa-induced Dyskinesia in Patients With Parkinson's Disease.

44. http://www.adamaspharma.com/ads5102/ website visited on 25-3-17.

45. Adamas Pharmaceuticals, Inc. et al. Amantadine compositions and methods of use CA Patent 2782556 A1, priority date December 2, 2009.

46. Kopsky DJ, Keppel Hesselink JM. A new combination cream for the treatment of severe neuropathic pain. J Pain Symptom Manage, 39(2): 9-10 (2010).
47. Kopsky DJ, Keppel Hesselink JM, Bhaskar A, Hariton G, Romanenko V, Casale R. Analgesic effects of topical ketamine. Minerva Anestesiol, 81(4): 440-449 (2015).

48. Keppel Hesselink JM, Kopsky DJ, AK Bhaskar. Skin matters! The role of keratinocytes in nociception: a rational argument for the development of topical analgesics. J Pain Res, 10: 1-8 (2017).

49. Keppel Hesselink JM, Kopsky DJ. Topical phenytoin in neuralgic pain, peripheral modulation of central sensitization: two case reports. J Pain Relief, 6(2): 284 (2017).

50. Keppel Hesselink JM, Kopsky DJ. Burning pain in small fibre neuropathy treated with topical phenytoin: rationale and case presentations. J Clin Anesth Pain Med, 1(1): 6 (2017).

51. Keppel Hesselink JM, Kopsky DJ. Phenytoin: 80 years young, from epilepsy to breast cancer, a remarkable molecule with multiple modes of action. J Neurol, 1-5 (2017).

52. Kopsky DJ, Keppel Hesselink JM. Phenytoin in topical formulations augments pain reduction of other topically applied analgesics in the treatment of trigeminal neuralgia. $J$. Clin Anesth, 38: 154-155 (2017).

53. Sun W, Sanderson PE, Zheng W. Drug combination therapy increases successful drug repositioning. Drug Discov Today, 21(7): 1189-1195 (2016). 